Available online at GSC Online Press Directory

GSC Biological and Pharmaceutical Sciences

e-ISSN: 2581-3250, CODEN (USA): GBPSC2

Journal homepage: https://www.gsconlinepress.com/journals/gscbps

(RESEARCH ARTICLE)

\title{
Effectiveness of plant extracts (lemon grass and tobacco) and insecticide Spinosad against Tribolium castaneum and Rhyzopertha dominica
}

\author{
Sakhi Laraib 1, Moon Bushra 1, Shaker Muhammad Afsar Ali 2, *, Arslan Muhammad 3, Rubab Sana 2, Shahzad \\ Muhammad ${ }^{3}$ and Awais Muhammad ${ }^{3}$
}

1 Department of zoology wild life \& fisheries, University of Agriculture, Faisalabad.

2 Department of Entomology, Bahaudin Zakariya University, Multan.

${ }^{3}$ Department of Entomology, University of Agriculture, Faisalabad.

Publication history: Received on 07 February 2020; revised on 15 February 2020; accepted on 19 February 2020

Article DOI: https://doi.org/10.30574/gscbps.2020.10.2.0036

\begin{abstract}
Stored grain products are damaged by various types of insects during preservation of T. castaneum and lesser grain borer are most dangerous insect of preserved food. Rhyzopertha dominica is inner feeder and influences the wide variety as good as high quality of grains. Spinosad insecticide are very potent to manipulate the stored grain pest. Current research work was performed in the Department of Entomology, University of Agriculture, Faisalabad. Five concentrations $0.01 \%, 0.02 \%, 0.03 \%, 0.04 \%, 0.05 \%$ along with one control treatment of Spinosad was formed in hundred ml of purified water from standard dilutions and 2, 4, 6, 8, 10\% concentrations of each plants were prepared. Treatments were applied to check their possible toxic effects against T. castaneum and $R$. dominica. The data were recorded after 24, 48 and 72 hours, treatment means were compared with the help of (THSD) test. Spinosad gave maximum mortality $89.77 \%$ as compared to plant extracts lemon grass and tobacco $38.55 \%$ and $40.00 \%$ against lesser grain borer. Spinosad gives maximum mortality $87.27 \%$ as compared to plant extract lemon grass and tobacco $34.55 \%$ and $29.09 \%$ against red flour beetle.
\end{abstract}

Keywords: Mortality; Spinosad; Red flour beetle; Lesser gain borer

\section{Introduction}

Rhyzopertha dominica and Tribolium castaneum (Herbst) cause great financial losses of stored wheat grains. The conservative way to manage these insect pests had been with the use of insecticides, either in a straight line apply to grains or by gas fumigation. However, concerns have arisen about the persistence of insecticide residues in grains which can be harmful to mammals [1]. Herbst is extremely frequent and mainly critical insect of preserved goods in all over the world and it is mostly present in warehouses, mills, stored grains and granaries. Together larvae as well as adults not simply nourish on new cereals however, they can as well nourish on grains previously attacked by another insect [2].

Tribolium castaneum (Herbst) (Coleoptera: Tenebrionidae), red flour beetle, is one of the major preserved cereals pests reported to cause damage to broad choice of items such as spices, nuts, dried fruits, cacao, flour, peas, beans and grains, but crushed cereal food stuffs like coat are their favorite food [3]. Spinosad decreased viable pesticides found on the fermentation goods of an actinomycete bacterium, has been tag which is used against two-hundred and fifty crops in more than fifty countries. Spinosad a commercial bacterial insecticide, from the actinomycete microbes Saccharin polypore Spinosad [4]. They were reported to be efficient against $R$. dominica on 11-13\% moisture wheat

\footnotetext{
${ }^{*}$ Corresponding author

E-mail address: Afsaraliagrarian@gmail.com
} 
stored at temperatures [5]. Nicotiana tabacum L. is a financial set spread generally during the region, having different chemical material, it is biologically active against natural enemies such as herbivorous bacteria, insects and fungi. Nicotine and nicotine are organic compounds naturally produced by tobacco plants used as insecticides [6].

Rhyzopertha dominica, the lesser grain borer, belonging to family Bostrichidae is a chief pest present both in temperate as well as in tropical regions of the world. It causes severe damage to stored grains which include maize, wheat, barley, sorghum and rice [7]. Rhyzopertha dominica is the crucial pest of stored grain which is normally controlled by using phosphine fumigant [8]. To control this pest, generally chemical maneuvers are applied but highly adaptive characteristics of $R$. dominica develop resistance to a range of contact insecticide [9].

Examination of insecticidal potential of Tobacco and Lemon grass as plant extract against Red flour beetle and Lesser grain borer. To study the relative toxicity of new chemistry insecticide Spinosad.

\section{Material and methods}

The material includes Tribolium castaneum, Spinosad, tobacco extracts, Cymbopogon plastic cans, sterilized wheat flour, rubber bands, fine cloth, sieves, incubator, fine brushes and electric grinder.

\subsection{Rearing of insects}

Collected insects of red flour beetle and lesser grain borer was transferred to sterile crystal jars covered with cotton. Each strain was individually labeled and housed separately in a growth chamber at $30 \pm 20^{\circ} \mathrm{C}$ and $70 \pm 5 \%$ relative humidity. Sterilized wheat and flour were used for lesser grain borer and red flour beetle feeding media. After 5 days, the adult worms were removed and placed in another tank to provide optimal conditions for hatching eggs and uniform $\mathrm{F}$ populations for infested grains and flour.

\subsection{Plant extracts bioassay}

Nicotiana tabacum and Cymbopogon plant materials was washed with distilled water, dried in a cool place and grinded with assistance of electrical grander to make it into powdered form. Extraction of plant materials was done using acetone as a flush by addition 50 grams of powder of each plant powder in $150 \mathrm{ml}$ of acetone in Erlenmeyer flasks. The flask was placed on a rotary shaker and rotated at $220 \mathrm{rpm}$ for 24 hours. Whitman filter paper was used for filtration. First, a 100\% stock solution of four dilutions of each extract was prepared in acetone. Solution was applied on filter paper and after dry place them in petri dishes. Control treatments 20 immature adults of red flour beetle and lesser grain borer were placed in the petri dishes. Insect mortality data is available at 24, 48 and 72 hours.

\subsection{Insecticide bioassay}

Five concentrations $0.01 \%, 0.02 \%, 0.03 \%, 0.04 \%, 0.05 \%$ along with one control treatment of Spinosad was prepared. $100 \mathrm{ml}$ of distilled water used from stock solution. With the help of syringe each meditation was pragmatic at the rate of $0.3 \mathrm{ml} /$ filter paper. This was applied regularly on filter paper and allowed to dry. In each dish twenty insects of lesser grain borer and red flour beetle are released. Their mortality data were collected after 24, 48 and 72 hours.

\section{Results}

Table 1 shows that the effect of Nicotiana tabacum against T. castaneum and R. dominica after 24, 48 and 72 hours. In which mortality of Tribolium castaneum was maximum after $72 \mathrm{hrs}$ at $10 \%$ dose and maximum mortality recoded was $34.55 \%$ after $72 \mathrm{hrs}$, while effects of Nicotiana tabacum against $R$. dominica was recoded were maximum mortality was $40 \%$ at $10 \%$ dose. 
Table 1 Mortality effect of Nicotiana tabacum against T. castaneum and $R$. dominica after different exposure time periods.

\begin{tabular}{lllll}
\hline \multicolumn{5}{c}{ Time periods } \\
\hline Insect & Dose & $\mathbf{2 4 h r s}$ & $\mathbf{4 8 h r s}$ & $\mathbf{7 2 h r s}$ \\
\hline \multirow{2}{*}{ T. Castaneum } & $(\%)$ & Mortality & & \\
& 2 & $8.62 \pm 1.72 \mathrm{c}$ & $7.15 \pm 1.38 \mathrm{c}$ & $10.91 \pm 1.40 \mathrm{c}$ \\
& 4 & $10.35 \pm 1.87 \mathrm{c}$ & $14.29 \pm 1.50 \mathrm{~b}$ & $16.37 \pm 1.56 \mathrm{c}$ \\
& 6 & $13.80 \pm 2.00 \mathrm{bc}$ & $17.86 \pm 1.65 \mathrm{~b}$ & $23.64 \pm 1.66 \mathrm{~b}$ \\
& 8 & $18.96 \pm 2.29 \mathrm{ab}$ & $25.01 \pm 1.80 \mathrm{a}$ & $27.28 \pm 1.78 \mathrm{~b}$ \\
& 10 & $25.87 \pm 2.43 \mathrm{a}$ & $28.58 \pm 1.96 \mathrm{a}$ & $34.55 \pm 1.99 \mathrm{a}$ \\
& 2 & $10.35 \pm 1.72 \mathrm{~d}$ & $12.51 \pm 1.38 \mathrm{c}$ & $16.37 \pm 1.40 \mathrm{c}$ \\
& 4 & $15.52 \pm 1.90 \mathrm{~cd}$ & $19.65 \pm 1.55 \mathrm{~b}$ & $21.82 \pm 1.49 \mathrm{c}$ \\
& 6 & $20.69 \pm 2.12 \mathrm{bc}$ & $23.22 \pm 1.71 \mathrm{~b}$ & $29.09 \pm 1.59 \mathrm{~b}$ \\
& 8 & $24.14 \pm 2.32 \mathrm{ab}$ & $30.36 \pm 1.80 \mathrm{a}$ & $32.73 \pm 1.78 \mathrm{~b}$ \\
& 10 & $31.04 \pm 2.44 \mathrm{a}$ & $33.93 \pm 1.95 \mathrm{a}$ & $40.00 \pm 1.99 \mathrm{a}$ \\
\hline
\end{tabular}

Table 2 shows that the mortality effect of Cymbopogon against T. castaneum and R. dominica after 24, 48 and 72 hours. In which mortality of Tribolium castaneum was maximum after $72 \mathrm{hrs}$ at $10 \%$ dose. Maximum mortality recoded was $29.09 \%$ after $72 \mathrm{hrs}$, while mortality effects of Cymbopogon against $R$. dominica was recoded were maximum mortality was $34.55 \%$ at $10 \%$ dose after $72 \mathrm{hrs}$ of exposure time period.

Table 2 Mortality effect of Cymbopogon against T. castaneum and R. dominica after different exposure time periods.

\begin{tabular}{lllll}
\hline Insect & & & \multicolumn{3}{c}{ Time periods } \\
& Dose & $\mathbf{2 4 h r s}$ & $\mathbf{4 8 h r s}$ & $\mathbf{7 2 h r s}$ \\
& $\mathbf{( \% )}$ & Mortality & & \\
\hline T. Castaneum & 2 & $3.45 \pm 1.54 \mathrm{c}$ & $1.79 \pm 1.38 \mathrm{~d}$ & $5.46 \pm 1.14 \mathrm{~d}$ \\
& 4 & $8.62 \pm 1.81 \mathrm{bc}$ & $8.94 \pm 1.49 \mathrm{c}$ & $12.73 \pm 1.26 \mathrm{c}$ \\
& 6 & $12.07 \pm 1.99 \mathrm{~b}$ & $14.29 \pm 1.65 \mathrm{bc}$ & $16.37 \pm 1.33 \mathrm{c}$ \\
& 8 & $15.52 \pm 2.10 \mathrm{ab}$ & $17.86 \pm 1.80 \mathrm{ab}$ & $23.64 \pm 1.51 \mathrm{~b}$ \\
& 10 & $20.69 \pm 2.18 \mathrm{a}$ & $23.22 \pm 1.95 \mathrm{a}$ & $29.09 \pm 1.62 \mathrm{a}$ \\
& 2 & $6.90 \pm 1.33 \mathrm{c}$ & $7.14 \pm 1.59 \mathrm{~d}$ & $10.91 \pm 1.14 \mathrm{~d}$ \\
& 4 & $10.35 \pm 1.49 \mathrm{c}$ & $12.51 \pm 1.66 \mathrm{~cd}$ & $18.19 \pm 2.49 \mathrm{c}$ \\
& 6 & $17.24 \pm 1.55 \mathrm{~b}$ & $19.65 \pm 1.81 \mathrm{bc}$ & $21.82 \pm 2.89 \mathrm{c}$ \\
& 8 & $20.69 \pm 1.76 \mathrm{ab}$ & $23.22 \pm 1.99 \mathrm{ab}$ & $29.09 \pm 2.99 \mathrm{~b}$ \\
& 10 & $25.87 \pm 1.88 \mathrm{a}$ & $28.58 \pm 2.26 \mathrm{a}$ & $37.85 \pm 1.62 \mathrm{a}$ \\
\hline
\end{tabular}


Table 3 shows that the mortality effect of Spinosad against T. castaneum and R. dominica after 24, 48 and 72 hours. In which mortality of Tribolium castaneum was maximum after $72 \mathrm{hrs}$ at $0.05 \%$ dose. Maximum mortality recoded was $87.27 \%$ after $72 \mathrm{hrs}$, while mortality effects of Spinosad against $R$. dominica was recoded were maximum mortality was $89.77 \%$ at $0.05 \%$ dose after $72 \mathrm{hrs}$ of exposure time period.

Table 3 Mortality effect of Spinosad against T. castaneum and R. dominica after different exposure time periods.

\begin{tabular}{|c|c|c|c|c|}
\hline & $(\%)$ & Mortality & & \\
\hline \multirow[t]{5}{*}{ T. Castaneum } & 0.01 & $29.83 \pm 1.57 c$ & $53.58 \pm 1.79 b$ & $65.46 \pm 1.82 \mathrm{~d}$ \\
\hline & 0.02 & $35.09 \pm 1.72 c$ & $55.36 \pm 1.90 \mathrm{~b}$ & $70.91 \pm 1.99 \mathrm{dc}$ \\
\hline & 0.03 & $43.86 \pm 1.99 b$ & $60.72 \pm 1.98 b$ & $74.55 \pm 2.32 \mathrm{bc}$ \\
\hline & 0.04 & $50.88 \pm 2.00 \mathrm{ab}$ & $71.43 \pm 2.12 \mathrm{a}$ & $80.00 \pm 2.41 \mathrm{ab}$ \\
\hline & 0.05 & $52.63 \pm 2.22 \mathrm{a}$ & $76.79 \pm 2.53 a$ & $87.27 \pm 2.57 \mathrm{a}$ \\
\hline \multirow[t]{5}{*}{ R. dominica } & 0.01 & $29.83 \pm 1.57 d$ & $53.58 \pm 1.96 \mathrm{c}$ & $65.46 \pm 2.15 c$ \\
\hline & 0.02 & $36.84 \pm 1.70 \mathrm{~cd}$ & $55.36 \pm 2.12 \mathrm{c}$ & $70.91 \pm 2.49 c$ \\
\hline & 0.03 & $43.86 \pm 2.00 \mathrm{bc}$ & $62.50 \pm 2.43 b c$ & $74.55 \pm 2.89 \mathrm{bc}$ \\
\hline & 0.04 & $50.88 \pm 2.11 \mathrm{ab}$ & $71.42 \pm 2.51 \mathrm{ab}$ & $83.64 \pm 2.99 \mathrm{ab}$ \\
\hline & 0.05 & $54.39 \pm 2.22 \mathrm{a}$ & $78.57 \pm 2.77 \mathrm{a}$ & $89.77 \pm 3.04 a$ \\
\hline
\end{tabular}

\section{Discussion}

The present research was conducted to assess the resistance in Rhyzopertha dominica (F) and Tribolium castaneum against insecticide Spinosad and plant extract tobacco and lemon grass. Populations of these insects were collected from various parts of district Jhang. These insects were exposed to five concentrations $(0.01,0.02,0.03,0.04$ and $0.05 \%)$ of Spinosad and five concentrations $(2 \%, 4 \%, 6 \%, 8 \%$ and $10 \%)$ of plant extract tobacco and lemon grass. Five concentrations $0.01 \%, 0.02 \%, 0.03 \%, 0.04 \%, 0.05 \%$ along with one control treatment of Spinosad was prepared. $100 \mathrm{ml}$ of distilled water used from stock solution. With the help of syringe each meditation was pragmatic at the rate of $0.3 \mathrm{ml} /$ filter paper. This was applied regularly on filter paper and allowed to dry overnight. In each dish, 20 insects of lesser grain borer and red flour beetle, and for 20 insects, wheat flour was supplied at a rate of $3 \mathrm{~g} / \mathrm{dish}$. Each concentration was repeated three times by using a completely randomized design. Their mortality data were collected after 24, 48 and 72 hours. Data regarding mortality was recorded after 24, 48 and 72 hours. Abbott formula was used to calculate mean mortality value was calculated by performing CRD. In this experiment first of all we checked the mortality rate in both insects. The chief objective of this study was to determine resistance level in $T$. castaneum and $R$. dominica. The results are similar to the [10] which revealed that the effectiveness of Spinosad depend on dose level and time exposure. With the increase in concentration and duration of time the mortality rate also increased. Herbst is extremely frequent and mainly critical insect of preserved goods in all over the world and it is mostly present in warehouses, mills, stored grains and granaries. Together larvae as well as adults not simply nourish on new cereals however, they can as well nourish on grains previously attacked by another insect [2]. Tribolium castaneum (Herbst) (Coleoptera: Tenebrionidae), red flour beetle, is one of the major preserved cereals pests reported to cause damage to broad choice of items such as spices, nuts, dried fruits, cacao, flour, peas, beans and grains, but crushed cereal foodstuffs like coat are their favorite food [3]. Table 1 shows that the effect of Nicotiana tabacum against T. castaneum and $R$. dominica after 24, 48 and 72 hours. In which mortality of Tribolium castaneum was maximum after $72 \mathrm{hrs}$ at $10 \%$ dose and maximum mortality recoded was $34.55 \%$ after $72 \mathrm{hrs}$, while effects of Nicotiana tabacum against $R$. dominica was recoded were maximum mortality was $40 \%$ at $10 \%$ dose. Table. 2 shows that the mortality effect of Cymbopogon against $T$. castaneum and R. dominica after 24, 48 and 72 hours. In which mortality of Tribolium castaneum was maximum after $72 \mathrm{hrs}$ at $10 \%$ dose. Maximum mortality recoded was $29.09 \%$ after $72 \mathrm{hrs}$, while mortality effects of Cymbopogon against R. dominica was recoded were maximum mortality was $34.55 \%$ at $10 \%$ dose after $72 \mathrm{hrs}$ of exposure time period. Table. 3 shows that the mortality effect of Spinosad against T. castaneum and $R$. dominica after 24, 48 and 72 hours. In which mortality of Tribolium castaneum was maximum after $72 \mathrm{hrs}$ at $0.05 \%$ dose. Maximum mortality recoded was $87.27 \%$ after $72 \mathrm{hrs}$, while mortality effects of Spinosad against $R$. dominica was recoded were maximum mortality was $89.77 \%$ at $0.05 \%$ dose after $72 \mathrm{hrs}$ of exposure time period. 


\section{Conclusion}

This study reveals that Spinosad gives excellent mortality the plant extracts against both insects as the same time plant extracts also giver considerable effects against red four beetle and laser grain borer. We concluded that Spinosad can be used against these both insects which is more helpful to control these insects than plant extracts.

\section{Compliance with ethical standards}

\section{Acknowledgments}

The authors declare that they have no conflict of interest.

\section{Disclosure of conflict of interest}

There is no conflict of interest among all the authors.

\section{References}

[1] Prates HT, JP Santos, JM Waquil, JD Fabris, AB Oliveira and JE Foster. (1998). Insecticidal activity of monoterpenes against Rhyzopertha dominica (F.) and Tribolium castaneum (Herbst). J. Stor. Prod. Res, 3, 243249.

[2] Sharaby A. (1988). Evaluation of Some Myrataceae Plant Leaves as Protectants Against the Infestation by Sitophilus oryzae L. and Sitophilus granarius L. Int. J. Tropical Insect Sci., 9, 465-468.

[3] Campbell JF and C Runnion. (2003). Patch exploitation by female red flour beetles, Tribolium castaneum. J. Insect Sci, 3, 44-49.

[4] MERTZ FP and RC Yao. (1990). Saccharopolyspora Spinosad sp. Nov. isolated from soil collected in a sugar mill rum still. Inter. J. System. Evol. Micro, 40, 34-39.

[5] Fang L, BH Subramanyam and F Arthur. (2002). Effectiveness of Spinosad against five stored product insects on four classes of wheat. J. Econ. Entomol, 95, 640-650.

[6] Al- Rawi A and HL Chakra arty. (1988). Medicinal Plants of Iraq. 2ndEd. Baghdad, Iraq.

[7] Rees D. (2004). Insects of stored products. CSIRO publishing, Australia, Sharma SS, Thapar VK, Simwat GS. 1979. Biochemical losses in stored wheat due to infestation of some stored grain insect pests. Bull. Grain Technol, 17, 144-7.

[8] Collins PJ, GJ Daglish, H Pavic and RA Kopittke. (2005). Response of mixed-age cultures of phosphine-resistant and susceptible strains of lesser grain borer, Rhyzopertha dominica, to phosphine at a range of concentrations and exposure periods. J. Stored Prod. Res, 41, 373-385.

[9] Opit GP, TW Phillips, MJ Aikins and M Hasan. (2012). Phosphine resistance in Tribolium castaneum and Rhyzopertha dominica from stored Wheat Oklahoma. J. Econ. Entomol, 105(4), 1107-1114.

[10] Nadeem M, Iqbal J and Assi MS. (2013). Effectiveness of Spinosad against Tribolium castaneum (Herbst) (Coleoptera Tenebrionidae). Gomal uni. J. res, 29(2), 17-25.

\section{How to cite this article}

Sakhi L, Moon B, Shaker MA, Arslan M, Rubab S, Shahzad M and Awais M. (2020). Effectiveness of plant extracts (lemon grass and tobacco) and insecticide Spinosad against Tribolium castaneum and Rhyzopertha dominica. GSC Biological and Pharmaceutical Sciences, 10(2), 156-160. 